International Journal of Modern Physics B

Vol. 26, No. 31 (2012) 1292003 (1 page)

(C) World Scientific Publishing Company

DOI: $10.1142 /$ S0217979212920038

ERRATUM

\title{
NONRECIPROCAL MULTIFERROIC SUPERLATTICES WITH BROKEN PARITY SYMMETRY
}

\author{
[Int. J. Mod. Phys. B, Vol. 26, No. 3 (2012) 1250021 (20 pages)] \\ ZHENGHUA TANG* and WEIYI ZHANG ${ }^{\dagger}$ \\ National Laboratory of Solid State Microstructures and Department of Physics, \\ Nanjing University, Nanjing 210093, China \\ *tangzh@smail.nju.edu.cn \\ †wyzhang@nju.edu.cn
}

Received 27 July 2011

Revised 12 October 2011

Due to a transmission error, Fig. 4 of the above article was published wrongly. The correct figure is:

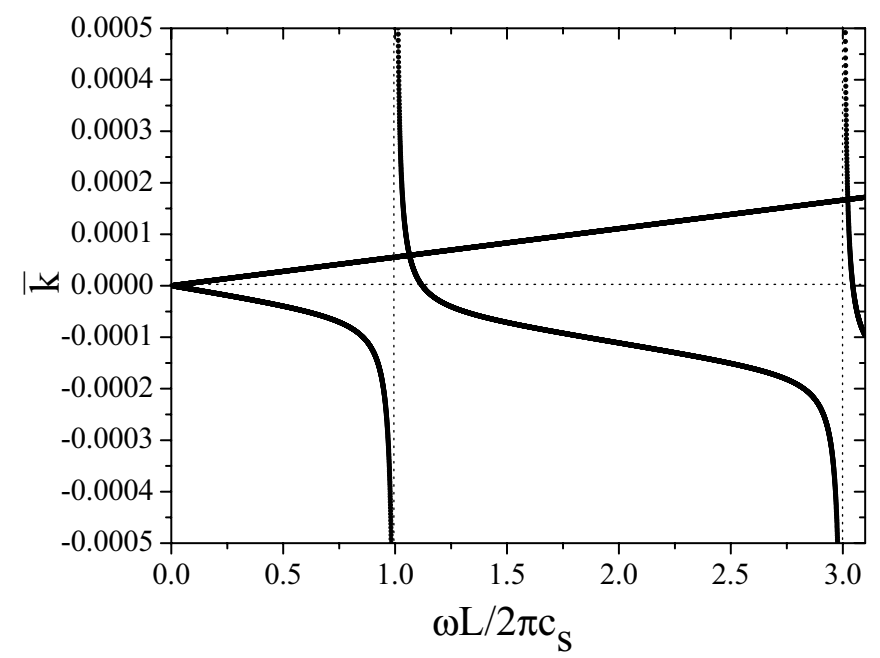

Fig. 4. The polaritonic band structures for multiferroic superlattice near the Brillouin zone center. The piezomagnetic coefficient is taken as $T_{31}=1.12 \times 10^{-9} \mathrm{~m} / \mathrm{A}$, the other material parameters are the same as Fig. 2. 